\title{
LAS COMUNIDADES INDÍGENAS Y LA RELACIÓN CON LA INDUSTRIA MINERA EN MÉXICO
}

\author{
The Indigenous Communities and the Relationship \\ With Mining Industry in Mexico
}

\author{
LINA MARÍA BASTIDAS-ORREGO1, BENITO RAMÍREZ-VALVERDE', \\ ALFREDO CESÍN-VARGAS², DANIEL MARTÍNEZ-CARRERA ${ }^{1}$, \\ JOSÉ PEDRO JUÁREZ-SÁNCHEZ ${ }^{1}$, HUMBERTO VAQUERA-HUERTA ${ }^{3}$
}

${ }^{1}$ Colegio de Postgraduados Campus Puebla- Programa de Doctorado en Estrategias para el

Desarrollo Agrícola Regional. Km. 125.5 Carretera Federal México-Puebla, Puebla, Pue. C.P. 72760.

2Universidad Nacional Autónoma de México. Unidad Académica de Estudios Regionales.

3 Colegio de Postgraduados - Campus Montecillo.

E-mail: bastidas.lina@colpos.mx

bramirez@colpos.mx

Recibido: 13 de Febrero de 2016

Aceptado: 31 de Marzo de 2016

\begin{abstract}
La industria minera ha jugado un papel preponderante en el crecimiento económico de México, y en general de los países latinoamericanos, no obstante, responde a un modelo económico extractivista, que se caracteriza por la apropiación de la tierra y la explotación de los recursos naturales, permitiendo la acumulación de capital a países extranjeros, especialmente a Canadá. El apogeo que ha tenido la minería se sustenta en una serie de impactos negativos, teniendo en cuenta el sistema económico predominante y la estrecha relación que los indígenas han tenido con esta industria desde tiempos prehispánicos, convirtiéndose en la colonia en una relación de esclavitud y abuso para las comunidades indígenas; a pesar del derecho que tienen sobre sus tierras y su propia identidad, desencadenando luchas por recuperar el poder y el control de su territorio. En este artículo se hace un análisis de los diferentes impactos que genera la minería y se presentan algunos casos de proyectos mineros que se han desarrollado en las últimas décadas en varios asentamientos indígenas de México.
\end{abstract}

Palabras claves: Comunidades indígenas, Proyectos mineros, Impactos de la minería.

\begin{abstract}
The mining industry has played a leading role in economic growth in Mexico, and in general Latin American countries, however, it responds to an extractivist economic model, characterized by the appropriation of land and exploitation of natural resources, allowing the accumulation of capital to foreign countries, especially Canada. The bloom of mining has been based on a series of negative impacts, taking into account the prevailing economic system and the close relationship that indigenous people have had with this industry since prehispanic times, becoming the colony in a relationship of slavery and abuse to indigenous communities; despite the right of their land and their own identity, and this has triggered struggles to regain power and control over its territory. This article presents an analysis of the different impacts generated by mining and some cases of mining projects that have developed in recent decades in several indigenous settlements of Mexico is presented.
\end{abstract}

Keywords: Indigenous communities, Mining projects, Mining impacts. 


\section{INTRODUCCIÓN}

La industria minera ha estado ligada a la economía mexicana desde la época de la colonia (Miranda 1992, Gaviria 2009), fue importante para financiar los proyectos de crecimiento de la corona española en el siglo XVIII, las políticas generadas en ese entonces mostraban una clara protección y preferencia hacia ella. Por otro lado, también ha estado vinculada con las comunidades indígenas mexicanas. En la época prehispánica se dio a través de la explotación de obsidiana; ya en la época colonial cuando la industria pasa a manos de los españoles y criollos, la relación entre la minería y los indígenas tomó una connotación negativa, por las condiciones laborales presentes en la época (Miranda 1992, Gaviria 2009).

Dado que una de las estrategias de la minería colonial fue el crecimiento basado en la mano de obra barata, se evidencian procesos de esclavitud hacia los indígenas y los negros, bajo el modelo de tandas o repartimientos. Es así como existían dos tipos de explotación de la fuerza de trabajo indígena: el repartimiento de indios y los indios naborios. El repartimiento de indios era una institución que se encargaba de obligar a las entidades territoriales a proporcionar un porcentaje de su población indígena para trabajar en las minas; por ejemplo, en Michoacán alcanzó hasta el $4 \%$ de la población indígena; sin embargo, el porcentaje variaba según el número de población, muertes por enfermedades, condiciones de la industria minera y de la legislación (Gaviria 2009). En este grupo a los indígenas no se les pagaba por su trabajo, es decir, eran considerados esclavos. En el segundo tipo de explotación, los indios naborios, se alquilaban a cambio de 4 o 5 reales por semana, de los cuales debían pagar al rey 1 peso y media fanega de maíz al año (Miranda 1992).

El trabajo en la minería colonial se caracterizó por ser esclavizante, utilizar la violencia hacia los indígenas mineros y aquellos que vivían cerca de la región minera, dado que estos eran recogidos y retenidos en las minas para realizar tareas duras y peligrosas. Además, los castigaban de forma humillante, violenta y en público.

La minería de aquella época consistía en introducirse en las profundidades de la tierra por huecos estrechos y sinuosos, con poca ventilación y luz, para extraer el mineral, después acarrearlo hasta la superficie; y por último hacer el beneficio del mineral, el cual en muchos casos debían de triturarse la amalgama con los pies, este último proceso era bastante peligroso porque la amalgama tenía mercurio, que generaba enfermedades en la piel de los indígenas. Las jornadas laborales eran de 12 horas para los que trabajaban en seco y 6 horas para los que lo hacían en agua (Gaviria 2009). Podría decirse entonces que la actividad minera era riesgosa, debido a las condiciones en que se realiza la extracción del mineral. Además, el nulo respeto a los derechos de los indígenas, y la existencia de una reglamentación que estuviera dispuesta a mitigar los riesgos y enfermedades, ocasionaban la mortandad de muchos de ellos por enfermedades o accidentes.

En un principio la relación inequitativa de los indígenas con la minería era casi exclusivamente un tema laboral y de distribución de ingresos; en la actualidad las condiciones de destrucción del medio ambiente hacen que sus comunidades se organicen en defensa de su territorio. Ahora, la minería sigue siendo importante para la economía mexicana. Esto se puede percibir en los actuales proyectos gubernamentales, donde se promueve un claro crecimiento de esta industria en el país, el cual no ha considerado a los pobladores de las amplias regiones donde se llevan a cabo estos proyectos, lo que está generando un incremento de los conflictos por la demanda intensiva de recursos naturales como la tierra y el agua por parte de las mineras. Esta situación afecta las actividades económicas y culturales de las comunidades indígenas, dado que también requieren los mismos recursos e interfieren en el autodesarrollo de las comunidades. Por otro lado, la tierra para los indígenas representa no sólo el sustento de sus familias, sino que hay una relación física y espiritual con ella, es parte de su cosmovisión y del desarrollo de las diferentes formas de vida de las comunidades.

Los conflictos socioambientales han aumentado en los últimos años, esto en parte debido al incremento en las concesiones mineras. La generación de impactos negativos en el medio ambiente también contribuye en el incremento de los conflictos. También es tema de conflicto los problemas territoriales, una falta de consulta previa e informada a las comunidades, la violación de los derechos humanos, y la lucha por obtener mayores beneficios para cualquiera de los actores (comunidades, empresa minera y gobierno) (Saaden-Hazin 2013). Sin embargo, y dada la importancia de la minería en las economías, el conflicto entre la expansión minera, los medios de vida y la sostenibilidad local, no es sólo un problema nacional, también es un asunto regional y mundial (Bebbington \& Bury 2010).

Teniendo en cuenta el panorama presentado, en este documento se realiza una revisión sobre la importancia económica de la minería para el país, y se presentan algunos de los casos sobre las comunidades indígenas que viven en algunas zonas mineras de México. Se espera que este artículo pueda ser un aporte a las personas que trabajen la relación entre la extracción de minerales y las comunidades indígenas, especialmente en América Latina. 
Ambiente y Sostenibilidad 2016 (6): 80-96

Revista del Doctorado Interinstitucional en Ciencias Ambientales

ISSN: 2339-3122

Digital

\section{LA MINERÍA EN MÉXICO}

La industria minera en México ha estimulado históricamente el desarrollo económico, su evolución llevó a la construcción de una red urbana minera, de ciudades consideradas como polos económicos, regiones prósperas o actuales capitales de estados de la República como: Guanajuato, San Luis Potosí, Pachuca, Taxco, Zacatecas, Saltillo y Durango, entre otras. Así, el desarrollo de la industria relacionó la actividad económica, con la estructura social y estas con el territorio (Sariego 1994). La infraestructura que se construyó en los reales de minas (sociedad colonial minera), ha sido útil para dinamizar la economía de esta red urbana.

Aunque la minería ha sido un apoyo para las economías, ha traído consigo altos costos, debido a que la industria minera opera bajo el modelo económico extractivista, al igual que en otros países subdesarrollados (Azamar \& Ponce 2014). Este modelo se caracteriza por la apropiación de la tierra y la explotación de los recursos naturales que se encuentren en el área. Es así, como las grandes mineras trabajan bajo un esquema extractivista, es decir, no generan encadenamientos productivos en la región donde operan y son socioambientalmente devastadoras, por el uso de agua, uso de energía y mano de obra barata (Delgado-Ramos 2010); por ejemplo, Ferrante (2015) muestra como en Argentina se ha intensificado el uso de la energía en la minería a gran escala, lo cual ha contribuido a aumentar la crisis energética por la que está pasando ese país.

Por otro lado, México y en general AL, responden a las necesidades capitalistas del mundo, siendo los principales proveedores de minerales y materias primas a nivel mundial, eso hace no sólo que México sea un país exportador, sino receptor de inversión extranjera, haciéndolo dependiente, debido a que depende de la acumulación de capital de otros países y a la transferencia de valor hacia el exterior (Delgado-Ramos 2010, PérezRincón 2014). Lo cual implica un uso cada vez mayor de la tierra y el usufructo de sus minerales por parte de empresas extranjeras, por tanto, se puede hablar de un despojo de tierras, recursos naturales y financieros (Delgado-Ramos 2010). Debido al incremento de uso de materias primas, las empresas que explotan recursos naturales, entre ellos los minerales, necesitan ampliar sus fronteras hacia nuevos territorios habitados por comunidades de diferente tipo: indígenas, campesinos, afrodescendientes e incluso habitantes de las ciudades; lo cual pone en riesgo el equilibrio en sus territorios (Pérez-Rincón 2014).

En el trabajo de (Vélez-Torres \& Ruiz-Torres 2015), presentan la acumulación neoliberal como un modelo económico que ha sido implementado en los países de $\mathrm{AL}$, especialmente en el sector minero. Las políticas neoliberales llevaron a incrementar la acumulación privada del capital, mediante políticas como la inversión extranjera, fomentando de alguna manera la extracción de recursos naturales. Los autores concluyen que, las políticas para incentivar la Inversión Extranjera Directa en minería han generado graves impactos ambientales, violación de derechos humanos y profundización de conflictos socio-ambientales, afectando de forma espacial a comunidades étnicas.

Por otro lado, en el trabajo de (Martínez-Coria \& Haro Encinas 2015), muestra como la fase actual de acumulación de capital por desposesión se basa en la intensificación de la transferencia y apropiación de los recursos naturales, los cuales algunos se extraen de territorios indígenas. Esto es posible gracias a los procesos de privatización que se han dado por las políticas de desregulación, favoreciendo el cambio en el uso del suelo y la extracción masiva de recursos.

A pesar del modelo extractivista que impera en México, en la actualidad, la minería se puede considerar como un sector importante en la economía nacional, esto se evidencia en las estadísticas que presenta el INEGI (2014), el cual ubica a esta industria como el cuarto renglón económico de mayor aportación al PIB en el período 2003 - 2011, por debajo del sector manufacturero, comercio y servicios inmobiliarios y de alquiler de bienes muebles.

En particular, según el informe World Mining Data (International Organizing Committee for the World Mining Congresses 2015), para el año 2013 México ocupó el catorceavo lugar en importancia en la producción de minerales en el mundo, con una producción de 239584211 millones de toneladas, lo que corresponde en dólares a 141160 millones de dólares, los principales países productores del mundo son China y Estados Unidos, quienes producen entre 4 y 5.5 veces más que México. No obstante, para el mismo año fue el primer productor de plata en el mundo con un volumen de 5827 toneladas aproximadamente; y el segundo lo comparten el bismuto con 824 toneladas, y fluorita con 1210477 toneladas producidas. Estas características hacen de México un país altamente minero.

La minería es un sector en crecimiento, que además se ha convertido en una estrategia para consolidar la estabilidad económica del país. De acuerdo con el Anuario Estadístico de la Minería (Secretaria de Economía \& Servicio Geológico Mexicano 2013), en los diez años previos al documento, la minería extractiva no petrolera creció en términos reales a una tasa promedio anual de $4.3 \%$, superando en más del doble el ritmo de crecimiento que mostró la economía en su 
conjunto durante el mismo periodo.

A pesar de que el 2014 fue un año de limitada demanda y una tendencia a la baja en los precios de los metales y minerales, la industria minera mexicana registró una tasa de crecimiento del $1.8 \%$, para este año el valor de la producción representó un monto de 272.3 mil millones de pesos mexicanos. Por otro lado, las exportaciones llegaron a los 17.1 mil millones de dólares, donde el $43.9 \%$ de estas ventas es representado por el rubro de los metales preciosos, mientras que el $48.8 \%$ por los metales industriales, y el restante son minerales no metálicos (Secretaria de Economía \& Servicio Geológico Mexicano 2014a).

Con respecto al número de concesiones, a partir del año 2005 los permisos o concesiones entregadas para realizar actividades mineras han tenido una tendencia creciente. Según el Anuario Estadístico de la Minería del 2006 (Secretaría de Economía \& Servicio Geológico Mexicano 2006), tan sólo para ese año había 22375 concesiones vigentes en el país, y para el final del 2014 ésta cifra aumentó a 25267 concesiones mineras, que cubren una superficie de 25632 mil hectáreas, lo que representa alrededor de $12.7 \%$ de la extensión del territorio nacional (Secretaría de Economía \& Servicio Geológico Mexicano 2014a), esto implica que en 8 años, la aprobación en las concesiones se incrementó en un 13\% aproximadamente.

Por ejemplo, en el Estado de Puebla, México; se encontró que para el 2014 el 8.73\% del territorio (297 023.5 hectáreas) está concesionado, representa en 427 títulos (Secretaria de Economía \& Servicio Geológico Mexicano 2014b). Allí operan al menos 20 minas de minerales no metálicos y 36 de material activo, ubicadas en algunas localidades de la Sierra Norte; y en la misma región hay dos proyectos de exploración de oro, plata, cobre y zinc (Secretaria de Economía \& Servicio Geológico Mexicano 2014b). Es importante resaltar que algunos de los proyectos en exploración se encuentran en zonas donde habitan comunidades campesinas e indígenas. El Estado de Puebla es uno de los principales productores de Calcita con una producción de 1506767 de toneladas representando el $28.99 \%$ del total de la producción nacional. A pesar de que existen títulos para exploración de oro, plata y cobre, en el informe de Panorama Minero del Estado de Puebla (Secretaria de Economía \& Servicio Geológico Mexicano 2014b) no se presenta información específica sobre la producción de estos minerales.

Dado que México es un país altamente minero, es considerado atractivo para el capital extranjero, es así como para el 2014 en el Anuario Estadístico de la Economía Mexicana (Secretaría de Economía \& Servicio Geológico
Mexicano 2014a) reportaba 266 empresas con capital extranjero operando en el país, las cuales manejaban un portafolio de 870 proyectos mineros. El $70 \%$ de las empresas extranjeras provienen de Canadá, el 17\% de Estados Unidos de América, los otros países con mayor participación son Australia, Inglaterra, Japón, China e India. No todos los proyectos de capital extranjero se encuentran en explotación, según éste mismo informe, el $73.10 \%$ se encuentran en etapa de exploración; sólo el $10.8 \%$ en producción; en etapa de desarrollo el $4.14 \%$ y 104 proyectos en postergación, esto es para su futura reactivación en un tiempo financieramente razonable, el resto están suspendidos. La mayoría de estos proyectos, es decir el $66 \%$, están asociados a oro y plata, y el $11.5 \%$ de los proyectos a cobre. El estado con mayor número de proyectos asociados a capital extranjero es Sonora, que cuenta con 212 proyectos, seguido de los Estados de Chihuahua y Durango, con 115 y 95 proyectos respectivamente (Secretaría de Economía \& Servicio Geológico Mexicano 2014a).

El fenómeno de generación de políticas para la captación de Inversión Extranjera no es exclusivo de México, en general, los países de Latinoamérica han abierto sus fronteras como respuesta a las políticas neoliberales, generando así que otros países entren a disputarse con las comunidades el control de sus recursos (Constantino 2015).

Por otro lado, las nuevas tecnologías que permiten la reducción de costos de explotación, el precio de los minerales, el incremento de la población y el incremento en los índices de consumo mundial, ha hecho que se aumente la demanda de los minerales en general; esto aunado a la importancia de las riquezas de minerales en el país, ha suscitado que el gobierno mexicano promueva una política de desarrollo minero basado en ventajas comparativas (Fuente \& Barkin 2013), lo que explica el aumento en la tendencia de los títulos concedidos a empresas nacionales y extranjeras.

México cuenta con una gran riqueza en minerales, su explotación ha venido incrementándose en las últimas décadas; no obstante, se ha evidenciado una caída en la ley de los minerales, es decir, una disminución en la proporción de mineral disponible por tonelada de materia procesada (Garay 2012). Esto implica el uso de tecnología de punta para incrementar la obtención de material, de igual forma requiere el tratamiento de cada vez más cantidad de materia procesada, esto significa que necesita mayor cantidad de tierra y excavaciones más profundas, de igual forma la tendencia al aumento de consumo de cantidades de energía para disponer de una misma cantidad de metal (Ferrante 2015). Lo anterior, sumado a las políticas gubernamentales y las nuevas tecnologías han generado cambios en la 
Ambiente y Sostenibilidad 2016 (6): 80-96

Revista del Doctorado Interinstitucional en Ciencias Ambientales

ISSN: 2339-3122

Digital

configuración geográfica minera, promoviendo que regiones mineras ya abandonadas sean reactivadas y regiones con baja ley puedan ser explotadas mediante minería a tajo abierto (Garay 2012).

Se debe tener en cuenta que la minería tiene importancia económica como fuente de materia prima para la industria manufacturera, militar, informática e incluso agrícola, este es un sector intensivo en capital, intensivo en tecnología y con altos niveles de captación de inversión extranjera, pero con impactos negativos irreversibles en el medio ambiente y en las comunidades.

\section{IMPACTO DE LA MINERÍA}

A pesar de la importancia económica que significa la extracción de minerales, existe la paradoja sobre el crecimiento económico en contraposición de la degradación ambiental y social que genera. Se considera que la minería produce impactos negativos debido a la evolución que hay en los procesos de expansión que se han venido presentando, estos han demandado de forma intensiva recursos naturales como tierra, agua, energía y minerales. Estas demandas de recursos entran en competencia con las actividades agrícolas de las comunidades indígenas (que también requieren recursos) y con actividades de conservación de los recursos naturales, los cuales son necesarios para preservar la biodiversidad y para la sobrevivencia de las comunidades locales y circundantes.

Estos impactos se explican, entre otras razones, porque la industria minera se encuentra bajo el marco de un modelo económico capitalista; es decir, bajo una economía que no se responsabiliza del calentamiento global, que no genera encadenamientos productivos ni procesos económicos locales importantes para el desarrollo de las comunidades adyacentes, concentra grandes extensiones de tierra y despoja de sus territorios a muchos pueblos originarios. Además, transfiere enormes recursos y ganancias a las grandes corporaciones, dejando sólo pobreza e importantes consecuencias sociales y ambientales, debido a que es un depredador de los recursos naturales (Contraloría General de la República de Colombia 2013).

La minería en México pasó de ser subterránea para ser operada como tajo a cielo abierto (Garay 2012); en estos procesos de extracción de los metales se cavan enormes y profundos cráteres sobre la tierra que dañan los mantos acuíferos; además, tanto las explosiones que provocan como los compuestos químicos que utilizan, para separar tanto el oro y la plata, contaminan el medio ambiente (Torixa 2012). Se ha escrito mucho sobre los impactos generados por la

industria minera y el modelo neoliberal en el que se ha venido desarrollando. Si bien, los impactos generados por la actividad minera son múltiples y muy complejos, pero no son siempre negativos; por lo que se presentarán a continuación los principales impactos, de índole diversa, que pueden afectar las condiciones de vida de las comunidades indígenas.

\section{Impacto socioeconómico}

Un estudio realizado por la Contraloría General de la República de Colombia (2013) afirma que la minería genera problemas y desigualdad social, esto se debe a que compite con el agro por el uso del suelo y otros recursos naturales. Resultando en fenómenos como la concentración de la tierra; cambios del uso del suelo, perdiendo así la funcionalidad de la vocación productiva; trayendo como consecuencia impactos en las condiciones de vida de las comunidades indígenas que viven en regiones mineras tales como: cambios en sus culturas, pérdida de identidad y problemas de seguridad alimentaria en la población, despojo de sus bienes, desplazamiento forzado de los campesinos o indígenas a otras zonas; lo cual lleva inevitablemente a conflictos entre las comunidades y las industrias de extracción minera.

Es así como la disputa del uso del suelo y el desplazamiento de comunidades por la minería es abordado por Hilson (2002), en su trabajo de investigación presenta un análisis en Australia de los impactos que han tenido los proyectos mineros en las comunidades indígenas que han habitado por cientos de años la tierra en la que se encuentran estos proyectos. Hilson afirma que esta situación es mucho más grave en países en desarrollo, como los países latinoamericanos, donde las intervenciones gubernamentales en estos conflictos son mínimas y los marcos regulatorios se quedan cortos o no se cumplen. En el último cuarto de siglo se evidencia más la preocupación del gobierno por la promoción de la inversión extranjera en este sector que la participación en resolver los conflictos por el uso de las tierras. Hilson (2000) afirma que el impacto social más significativo es el cultural, dado que la minería se desarrolla en poblaciones rurales y en algunas ocasiones regiones rurales indígenas, que comúnmente son grupos de personas en condiciones de pobreza, donde su economía local se basa en la agricultura, la artesanía y la pesca. Son comunidades pequeñas y poco expuestas a la globalización, lo que las hace más vulnerables a los impactos negativos de la industrialización y en general de la globalización.

De acuerdo a la CEPAL (2003), la actividad minera genera cambios en el territorio y en las tradiciones, modificando así la riqueza cultural y los comportamientos sociales, lo que 
implica aumento en los índices de drogadicción, alcoholismo, prostitución y violencia intrafamiliar. Sin embargo, el desarrollo de una industria minería puede promover el fortalecimiento del capital humano a través de capacitación tecnológica, incremento en los niveles de escolaridad, aumento en los indicadores sanitarios, mejoramiento y en algunos casos construcción de la infraestructura, y por ende "mayor calidad de vida". Estas mejoras en la calidad de vida se vuelven factores de atracción para el desplazamiento de la población, fomentando la migración, lo que implica una afectación de las condiciones culturales de las poblaciones indígenas originarias, ya que son influenciadas por otros valores, creencias, estructuras de pensamiento y formas de consumo externas. En contraste con la CEPAL, Hernández \& Montalvo (2011), en un estudio sobre la minería en el municipio de Zacatlán, concluyen que el desarrollo minero en la región a diferencia de la generación de desarrollo que la población esperaba, ocasionó el deterioro ambiental, social y económico de la región.

Si bien, en la época de los reales de minas, las regiones mineras se acondicionaban para producir los bienes y servicios necesarios, ahora la configuración de los territorios mineros es diferente, las tierras están destinadas a la minería (Gaviria 2009), lo cual podría llevar a un incremento de precios dado el aumento de la demanda, lo cual debe subsanarse con el abastecimiento de productos desde otras regiones. Además del incremento en los precios, puede generar una disminución de la renta local por descenso de la productividad agrícola y animal originada por los impactos en el ambiente que afectan el suelo, el agua, el aire, la flora y la fauna.

Dado el modelo de acumulación por desposesión, el cual predomina en la industria minera, dónde las políticas se han llevado bajo procesos intensivos en capital y uso de energía, generando el despojo de pueblos y comunidades, impactando negativamente el ambiente y los recursos naturales, agotamiento de recursos no renovables, trayendo enfermedades y pobreza a las comunidades; es lógico que las comunidades indígenas respondan de forma negativa sobre los proyectos mineros, estas respuestas se dan a través de diferentes estrategias; por ejemplo, la conformación de movimientos de resistencia social que nacen de los grupos comunitarios organizados, llevando consigo costos sociales y económicos no cuantificados, haciendo de su lucha una búsqueda por el control colectivos de los recursos, por el derecho a la autodeterminación de sus propias condiciones de existencia y contra el despojo de sus tierras, recursos naturales y saberes ambientales tradicionales (Navarro Trujillo \& Pineda Ramírez 2009). Las comunidades ante estas luchas se encuentran normalmente en situación desfavorable, dado que las leyes estimulan la expansión minera y la captación de capital extranjero.

\section{Impacto ambiental}

Los impactos ambientales generados por la minería a cielo abierto sobre la biodiversidad y las comunidades humanas son múltiples. Normalmente estos impactos ambientales se transfieren en forma de costos económicos y de salud para las comunidades aledañas. La población ante el deterioro del ambiente, debe invertir en mejorar la salud, las condiciones del suelo y en términos generales el medio ambiente. En los casos extremos ya sea por el deterioro ambiental o por despojo, la población puede perder su patrimonio y verse obligada a abandonar su comunidad en busca de medios de vida a otras zonas rurales o urbanas. También estos costos son asumidos por el gobierno en general, aunque no se pueden considerar sino hasta varios años después (Moran 2010).

La CEPAL (2003), afirma que la actividad minera puede llegar a destruir el hábitat, fragmentarlo o alterar sus características naturales. En cuanto a los ecosistemas, la minería a cielo abierto puede reducir la vegetación, poniendo en riesgo las especies animales y vegetales. También se genera la huida de fauna de la región y extinción por muerte, ante una alteración drástica de su hábitat. Según Sánchez (2000), los impactos de la minería sobre los ecosistemas se clasifican en cuatro categorías: destrucción de hábitats, su fragmentación, la alteración de sus características e impactos sobre la fauna. Lo cual lleva la disminución de la flora, agua y aire contaminado y aceleración de la erosión.

Por otro lado, el recurso agua se ve afectado por varias formas, por ejemplo, la presencia de sólidos en suspensión aumenta la turbidez y disminuye los rangos de luminosidad, esto impacta en los procesos biológicos de la fauna y la flora que habita en los medios acuáticos.

En el estudio realizado por Hernández \& Montalvo (2011), en el municipio de Zacatlán Puebla, donde se desarrolla la minería a cielo abierto de Feldespato, encontraron que dicha actividad requiere enormes cantidades de agua, las cuales propician la reducción del nivel freático de la zona, esto significa que ha secado pozos y manantiales, provocando el desabastecimiento de agua en la región y el encarecimiento del líquido; además, el agua es contaminada por el drenaje ácido ante la mezcla de polvo - agua, lo que a su vez reacciona con otros minerales expuestos, creando un vertido de material tóxico ácido con duración indefinida. Esto ha perjudicado la zona urbana del municipio, los cultivos y ganado de campesinos de al menos cuatro comunidades. 
En el mismo estudio (Hernández \& Montalvo 2011), hallaron que la minería a cielo abierto requirió de la deforestación de los bosques primarios, causando una rápida y fluida escorrentía de las precipitaciones pluviales, empeorando en los períodos de lluvia debido a que el suelo no puede retener el agua, además los suelos de las zonas donde se desarrolla la minería a cielo abierto están permanentemente erosionados y presentan montones de residuos de material estéril, que suelen formar enormes montañas a veces mayores que la superficie explotada.

Los impactos ambientales se evidencian en la destrucción de la flora y la fauna, sedimentación de ríos, disminución de la biodiversidad, contaminación del aire, deterioro por el uso indiscriminado del agua; este último se identifica porque el agua no es tratada adecuadamente para reintegrarla al medio ambiente, ya sea para el uso ecológico o de la población rural (Hilson \& Busu 2003, Sarrasin 2006).

Con respecto a la contaminación atmosférica, las principales fuentes de contaminación son las emisiones de partículas en el caso de la minería de carbón, arcilla y cal; los vapores tóxicos en el caso de la utilización de mercurio y cianuro para la amalgamación del oro, el ruido y las vibraciones producidas por la utilización de maquinaria, equipos y explosivos.

Además de los impactos ambientales, la minería a cielo abierto también genera problemas de salud debido a que se incrementa la contaminación con el polvo suspendido en el aire, sumado a esto están los gases, ruidos, vibraciones de la maquinaria, explosiones, etc.

Para terminar el tema ambiental, el nuevo sistema geográfico minero produce "Paisajes de sacrificio" (Garay 2012), es decir, destrucción paisajística en sus núcleos mineros generalmente en lugares periféricos o apartados; la transferencia de riqueza se da en los centros metropolitanos del sistema global mundial, donde accionistas, funcionarios y población vinculada, gastan sus ganancias y construyen su mundo social (Garay 2012).

No obstante, entre algunos proyectos de responsabilidad social y ambiental que han realizado empresas mineras en México, se pueden identificar el trasplante de flora nativa, recolección de semillas para conservación y germinado en vivero, reubicación de nidos o refugios, instalación de bebederos para aves, protección a especies endémicas, recuperación y almacenamiento de la capa superior del suelo, implementación de sistemas de supresión de polvo, manejo de residuos y combustibles, destoxificación del suelo, entre otras (Secretaria de Economía 2005). Pero al parecer estas acciones son insuficientes ante la magnitud de la destrucción ambiental que se produce cada vez que hay actividad extractiva.

\section{Impacto en el sistema político}

Los impactos políticos se refieren a las debilidades institucionales causadas por las influencias de los poderes económicos sobre las políticas gubernamentales, estatales y municipales. Es así como la debilidad institucional podría inferirse en una normatividad deficiente, en otro caso, las instituciones gubernamentales no tienen la capacidad de hacer cumplir adecuadamente las reglamentaciones, ya sea por corrupción, por ineficiencia, por desconocimiento, entre otras. Es así como hay una modificación al Artículo 27 de la Constitución Política de los Estados Unidos Mexicanos, donde la tierra y las agua comprendidas dentro de los límites del territorio nacional pueden constituirse en propiedad privada, no obstante, en la Ley de Minería de 1992 la minería tiene prioridad sobre cualquier actividad económica, dejando en desventaja a los indígenas y campesinos que habitan estas regiones.

Por otro lado, están las políticas neoliberales adoptadas por los gobiernos, tal como lo deduce (Martínez-Coria \& Haro Encinas 2015), han generado una guerra contra los pueblos originarios, confluyendo en estos espacios las fuerzas legales y coercitivas del Estado con las empresas capitalistas, y las del crimen organizado. Esto ha llevado a la invasión de territorios, el despojo de sus lugares de residencia y modos productivos tradicionales, el saqueo de recursos, la afectación del medio ambiente, la criminalización de la movilización y las resistencias, todo lo cual amenaza a la supervivencia de estos pueblos y sus formas vitales.

\section{LOS INDIGENAS Y LA RELACIÓN CON LA TIERRA}

La tierra ha sido un elemento fundamental en el desarrollo y supervivencia de los pueblos indígenas, por tanto, la relación existente entre la tierra y los indígenas no sólo se limita a un factor económico que es necesario para la producción de su alimento, también tiene connotaciones sociales y culturales bastante fuertes. Tanto Viqueira (2002) como Wolf (1971) en sus trabajos, identifican a la tierra como un factor esencial para la supervivencia de las comunidades indígenas y campesinas, desde la época colonial hasta la fecha. La tenencia de la tierra es un medidor de las divisiones sociales, y de alguna manera está presente en la conformación de comunidades; es la base de la identidad étnica de la comunidad. Es la tierra la que permite al indígena campesino tener lo que requiere para alimentarse, además le permite tener excedentes necesarios para vivir en 
una sociedad donde se debe de pagar impuestos, adquirir productos manufacturados, servicios externos para la familia y para la comunidad, y tener excedentes para cubrir los fondos de remplazo y los fondos ceremoniales. Es así, como se puede elucidar en el trabajo de Wolf, que la tierra es lo más importante para el campesino; este análisis aplica con mayor razón al campesino indígena.

La relación indígena - tierra va más allá de la simple concepción de ser un factor productivo que permite la sobrevivencia humana dentro de una estructura social, para los indígenas la tierra también representa un simbolismo. De hecho, el poder establecerse en un territorio, permitió que las comunidades cambien su condición de nómadas a sedentarios. Cada comunidad indígena tiene simbolismos diferentes; no obstante, la tierra y los recursos naturales en general están relacionados con la religión, con sus mitos y leyendas, con lo sagrado, es decir, con su cosmovisión. Por ejemplo, para la etnia huichol, las fuerzas y los elementos de la naturaleza son percibidos como deidades, de la misma forma que son considerados antepasados y parientes. Dentro de su territorio se encuentran santuarios, los cuales son lugares sagrados, que son visitados periódicamente a través del peregrinaje ritual, de los más importantes está el territorio de los Wirikuta, caso que se tratará en un apartado más adelante (Neurath y Pacheco, sin fecha).

Guevara-Romeroet al. (2015), hacen un análisis de la identidad de los grupos étnicos de la Sierra Norte de Puebla y la relación que hay con el aprovechamiento de los recursos naturales. En esta región las comunidades indígenas en su mayoría son de las etnias nahua y totonaca, se caracterizan por tener un arraigo con sus tierras y sus principios están basados, en parte, en la relación del hombre con la tierra, donde la imposición o propiedad de la tierra no es considerada dentro de su pensamiento, esto determina diversas formas de aprovechamiento de la tierra y los recursos. La cosmovisión de un pueblo permite identificar al territorio no como un simple lugar donde habitan, sino que es una relación colectiva de un pueblo con la tierra y los recursos con los que cuenta este lugar o área, es así como esta relación también está ligada a un ámbito religioso, a los saberes, costumbres y conocimientos. Desde este punto de vista, cualquier cambio de uso de suelo en estas comunidades, representa no sólo fuertes transformaciones en los ecosistemas, sino también en su cosmovisión y todo lo que comprende este concepto.

Por otro lado, para la comunidad nahua es tan importante la tierra, que al momento de sembrar las semillas de maíz, realizan la ceremonia del xinachtlacualtiliztli, en la cual solicitan permiso a la tierra para sembrar, pidiéndole buenos frutos y protección contra los roedores (Báez-Jorge \&
Gómez, 2000). Desde los olmecas, la preparación de la parcela y la siembra están relacionadas con numerosas ofrendas a la Madre Tierra (Florescano 2003). Para la etnia nahua el universo está compuesto por tres planos superiores que son: el celeste, el terrestre y el inframundo; donde la tierra es el plano principal. Hay otra concepción del universo, donde se representa en una pirámide con cuatro esquinas, en esta idea, la tierra también es el eje central. Ellos consideran que el hombre es el agente que tiene el poder de destruir o preservar el equilibrio, razón por la cual debe cuidar su conducta y el uso indebido de la superficie terrestre; esto es, porque la tierra es el equilibrio entre el cielo y el inframundo (Báez-Jorge \& Gómez 2000).

Además de la concepción simbólica de la superficie de la tierra, los indígenas también tenían un concepto sobre el subsuelo o interior de la tierra. Todos los pueblos indígenas mesoamericanos, concibieron el interior de la tierra (inframundo) como el lugar de regeneración más importante del Cosmos, donde habitan las fuerzas progenitoras de los astros, la vegetación y los seres humanos "...En sus orígenes los pueblos mesoamericanos concebían el interior de la Tierra como una gran boca devoradora, por la que periódicamente desaparecían los seres humanos, las semillas y los astros" (Florescano 2003). En general, el inframundo era lo opuesto a lo celeste, es decir, frío y oscuro; se asociaba al sacrificio, a la enfermedad y a la muerte. Actualmente para la étnica mixteca, la tierra es considerada la matriz y la lluvia el semen que la fertiliza.

No sólo en Mesoamérica, la tierra es considera un elemento sagrado y religioso, también en Sudamérica. En Colombia, los grupos indígenas han desarrollado una compleja relación con el medio natural circundante, una relación cruzada por tradiciones y rituales, definiéndolo como un territorio ancestral o territorio propio. Por ejemplo, los Wayuu, en la Guajira, delimitan y reafirman sus territorios, mediante sus cementerios (ACNUR 2008). Los Wayuu han tenido conflictos debido a los grandes proyectos carboníferos que han sido concesionados en las últimas décadas. Otro ejemplo que se puede citar en el trabajo de la ACNUR, es como la comunidad Arhuaca considera a su territorio sagrado (Sierra Nevada de Santa Marta). En la sierra cada elemento de la naturaleza tiene un nombre y una función, y están relacionados con las historias tradicionales de su dirigente espiritual (Mamö). Para los pueblos indígenas colombianos, la tierra y sus recursos constituyen una unidad. En algunas cosmologías consideran que hay un enlace entre la sociedad, la naturaleza y el mundo espiritual. También, consideran que el territorio es el lugar de los ancestros y morada de los dueños o amos de las plantas y los animales; además, consideran que la tierra es como la madre, y el territorio ocupado constituye la base para su reproducción biológica y cultural. 
Ambiente y Sostenibilidad 2016 (6): 80-96

Revista del Doctorado Interinstitucional en Ciencias Ambientales

ISSN: 2339-3122

Digital

\section{Los derechos territoriales de los grupos indígenas y la} minería

Los pueblos indígenas han estado en la mira de organizaciones internacionales, a través de la búsqueda de mecanismos legales supranacionales con el objetivo de protegerlos y mantener su existencia.

Los derechos humanos obligan a los estados a proteger y promover los derechos de sus ciudadanos. Con respecto a los indígenas, el derecho a existir es un derecho social, además que no se les puede privar de sus medios de subsistencia, tales como: ríos, bosques, mares y otras fuentes de sustento (Orellana 2009).

La Convención 169 de la OIT (Organización Internacional del Trabajo), es el único tratado que aborda el tema de las comunidades indígenas y los derechos de la tierra. El tratado garantiza a los pueblos indígenas el control sobre sus tierras, su status legal y su desarrollo. También protege su medio ambiente de la intromisión dañina de elementos ajenos y define las estructuras internas de la organización comunitaria (Orellana 2009). Este convenio busca que los derechos de propiedad de los pueblos indígenas estén bajo una protección especial, además señala que deben reconocerse los derechos de pertenencia y posesión de los pueblos en relación con las tierras que tradicionalmente han ocupado. También exigen que se hagan consultas previas a los indígenas aun cuando los recursos naturales permanezcan bajo propiedad estatal, tal como se menciona a continuación:

"En los casos en que el Estado sea propietario de los recursos minerales o subterráneos, o tenga derechos sobre otros recursos que forman parte de las tierras, los gobiernos deben determinar los procedimientos mediante los cuales consultarán la opinión de estos pueblos, con miras a establecer hasta qué punto se verían afectados los intereses de éstos, antes de ejecutar o autorizar cualquier programa de exploración o explotación de los recursos que formen parte de las tierras de dichos pueblos." (Orellana 2009).

Se han dado pasos importantes en los países como Colombia y Bolivia frente a la defensa de los territorios indígenas con respecto a los proyectos de explotación minera, dado que en sus códigos mineros contemplan el derecho de consulta previa a las comunidades (Revenue Watch Institute 2011). En Colombia, la reglamentación implica que sí la comunidad no otorga la licencia social, el proyecto no puede pasar de la etapa de exploración minera (Código de Minas de Colombia). A pesar de que México está adherido a la Convención 169 de la OIT, en su código minero los procedimientos de las consultas previas no están legislados ni reglamentados.

Probablemente surgirán otros tratados internacionales que encaminen a los pueblos indígenas a la recuperación y control de sus territorios ancestrales. Mientras tanto, son los gobiernos estatales los que tienen el reto de hacer cumplir las normas internacionales. Por el momento, los pueblos indígenas siguen perdiendo sus tierras y siendo desplazados o despojados de su territorio.

$\mathrm{Si}$ bien, México mediante el Artículo Segundo de su Constitución Política, en el inciso A parágrafo V, reconoce a los pueblos indígenas la autonomía para conservar y mejorar el hábitat y preservar la integridad de sus tierras; sin embargo, en el parágrafo VI promueve el uso y disfrute preferente de los recursos naturales de los lugares que habitan y ocupan las comunidades, salvo aquellos que corresponden a las áreas estratégicas, en términos que señala la misma Constitución. Dichas áreas estratégicas pueden ser los lugares donde se encuentren yacimientos de minerales con posibilidades de explotar, así estas áreas pueden entregarse a particulares en concesiones, de acuerdo al Artículo 27 de la misma Constitución. Lo anterior, hace que las comunidades indígenas no tengan una seguridad jurídica frente a la tenencia de las tierras, que son la herencia de sus ancestros.

\section{MINERÍA Y COMUNIDADES INDÍGENAS EN MÉXICO}

De acuerdo al Artículo $2^{\circ}$ de la Constitución, son comunidades integrantes de un pueblo indígena, aquellas que formen una unidad social, económica y cultural, asentadas en un territorio y que reconocen autoridades propias de acuerdo con sus usos y costumbre. En el mismo artículo, sugiere que además se debe tener en cuenta criterios etnolingüísticos y de asentamiento físico. En México, según la Comisión Nacional para el Desarrollo de los Pueblos Indígenas (2014), existen 68 pueblos indígenas con su propia lengua, están dispersos en todo el territorio nacional, con una concentración en las regiones interiores del país, regiones de difícil acceso y en zonas desérticas, montañosas o selva. El 40\% de las localidades del país tiene población indígena, representando para el 2010 una estimación de 15.7 millones de personas. En el mismo documento, se calcula que para el 2012 hay 8.2 millones en situación de pobreza y 3.5 millones en situación de pobreza extrema.

Es importante resaltar que algunas de las concesiones mineras que hay actualmente en el país se encuentran dentro de los territorios de 42 pueblos indígenas, según la 
tabla 1 hay 2211469 hectáreas concesionadas dentro de dichos territorios, esto arroja que el $17.6 \%$ en promedio del territorio indígena, enfrenta o enfrentará alguna actividad minera. La mayoría de estas concesiones están en etapa de exploración, es decir, el equivalente a 106833 hectáreas concesionadas.

Tabla 1. Extensión de concesiones mineras en territorios de pueblos indígenas.

\begin{tabular}{|c|c|c|c|c|c|c|c|}
\hline $\begin{array}{l}\text { Pueblo } \\
\text { indígena }\end{array}$ & $\begin{array}{l}\text { Territorios de } \\
\text { los pueblos } \\
\text { indígenas (ha) }\end{array}$ & $\begin{array}{c}\text { Extensión de } \\
\text { las } \\
\text { concesiones } \\
\text { mineras en } \\
\text { territorios } \\
\text { indígenas (ha) }\end{array}$ & $\begin{array}{c}\% \text { del } \\
\text { territorio } \\
\text { indígena }\end{array}$ & $\begin{array}{l}\text { Pueblo } \\
\text { indígena }\end{array}$ & $\begin{array}{l}\text { Territorios de } \\
\text { los pueblos } \\
\text { indígenas (ha) }\end{array}$ & $\begin{array}{c}\text { Extensión de } \\
\text { las } \\
\text { concesiones } \\
\text { mineras en } \\
\text { territorios } \\
\text { indígenas (ha) }\end{array}$ & $\begin{array}{c}\% \text { del } \\
\text { territorio } \\
\text { indígena }\end{array}$ \\
\hline Chatino & 223077 & 65667 & 29.4 & $\begin{array}{l}\text { Náhuatl GRO } \\
\text { Altiplano } \\
\text { EDOMEX OAX }\end{array}$ & 665574 & 45617 & 6.9 \\
\hline $\begin{array}{l}\text { Chichimeca } \\
\text { Jonaz }\end{array}$ & 4396 & 615 & 14.0 & $\begin{array}{l}\text { Náhuatl SLP } \\
\text { SNP NVER } \\
\text { Náhuatl }\end{array}$ & 948680 & 38313 & 4.0 \\
\hline Chol & 796544 & 1993 & 0.3 & $\begin{array}{l}\text { Zongolica - } \\
\text { Pico de } \\
\text { Orizaba }\end{array}$ & 348988 & 3151 & 0.9 \\
\hline $\begin{array}{l}\text { Chontal de } \\
\text { Oaxaca }\end{array}$ & 135933 & 5222 & 3.8 & $\begin{array}{l}\text { Náhuatl de } \\
\text { Durango }\end{array}$ & 36582 & 5578 & 15.2 \\
\hline Cochimi & 7599 & 522 & 6.9 & $\begin{array}{l}\text { Náhuatl de } \\
\text { Michoacán }\end{array}$ & 76218 & 39742 & 52.1 \\
\hline Cora & 367047 & 121028 & 33.0 & Otomi & 489646 & 30748 & 6.3 \\
\hline Cucapa & 153688 & 62214 & 40.5 & Paipai & 68326 & 66360 & 97.1 \\
\hline Guarijio & 83014 & 27699 & 33.4 & Pame & 104479 & 3005 & 2.9 \\
\hline $\begin{array}{l}\text { Huasteco } \\
\text { (Tenek) }\end{array}$ & 250611 & 2805 & 1.1 & Pima & 53767 & 27349 & 50.9 \\
\hline Huave & 106879 & 6237 & 5.8 & Popoluca & 103446 & 39373 & 38.1 \\
\hline Huichol & 832951 & 63285 & 7.6 & Quiché & 32414 & 279 & 0.9 \\
\hline Kanjobal & 29918 & 59 & 0.2 & Seri & 212222 & 5255 & 2.5 \\
\hline Kikapoo & 7040 & 4598 & 65.3 & $\begin{array}{l}\text { Tarahumara } \\
\text { (Raramuri) }\end{array}$ & 2647372 & 634457 & 24.0 \\
\hline Kiliwa & 27557 & 23479 & 85.2 & $\begin{array}{l}\text { Tepehuán } \\
\text { (Odam) }\end{array}$ & 1182536 & 272.536 & 23.0 \\
\hline Mame & 35796 & 2377 & 6.6 & Tlapaneco & 294429 & 74055 & 25.2 \\
\hline Maya & 7441968 & 69912 & 0.9 & Tzeltal & 924774 & 459 & 0.0 \\
\hline Mayo & 321124 & 33174 & 10.3 & Tzotzil & 774323 & 7115 & 0.9 \\
\hline Mazahua & 125482 & 12477 & 9.9 & Yaqui & 449320 & 9318 & 2.1 \\
\hline Mazateco & 315254 & 727 & 0.2 & Zapoteco & 1775199 & 280272 & 15.8 \\
\hline Mixe & 681045 & 7845 & 1.2 & Zoque & 674455 & 19255 & 2.9 \\
\hline $\begin{array}{l}\text { Mixteco } \\
\text { Náhuatl del }\end{array}$ & 1702341 & 92538 & 5.4 & & & & \\
\hline $\begin{array}{l}\text { Sur de } \\
\text { Veracruz }\end{array}$ & 96293 & 4759 & 4.9 & Total & 25608307 & 2211469 & 8.6 \\
\hline
\end{tabular}

Fuente: Boege (2013).

Como ya se ha mencionado, la relación que hay entre minería y pueblos indígenas en México, conlleva una serie de conflictos ya sea por riesgo o afectaciones socioambientales. Tal como lo afirma Paz (2014), los conflictos socioambientales actuales se dan en el ambiente mismo, desde lo ecológico, económico y sociocultural, disputando desde posiciones de poder. Esto hace que los conflictos sean procesos sociales complejos. Según Paz (2014), no hay negociación en esta clase de conflictos, debido a que lo que se busca es la existencia social de uno de los grupos en disputa. Cuando se habla de afectaciones socioambientales en el documento, se refiere a las 
implicaciones de forma negativa sobre la sociedad y el ambiente. En general, los principales riesgos o afectaciones son de contaminación al agua, destrucción de bosque, uso de fuentes hídricas, deterioro del ambiente e infraestructura, despojo y afectaciones a la salud.

Como señala la Revenue Watch Institute (2011), crecen tanto las inversiones en la actividad extractiva, como los conflictos generados. Algunos conflictos presentados muestran como los pobladores aledaños a los proyectos mineros solicitan la suspensión o cancelación de los mismos; o bien, negocian fuertemente las condiciones por la presencia de estos, reclamando compensaciones a las externalidades negativas que se puedan generar. Esta demanda por parte de las comunidades se argumenta en los impactos generados por la minería.

De acuerdo a Amnistía Internacional (2014), la estrategia de los pueblos indígenas para luchar por sus derechos ha sido el poder obtener el control de sus territorios, los cuales poseen abundantes recursos naturales. Con frecuencia, los indígenas han sido desplazados por los gobiernos y las multinacionales del sector energético, los cuales requieren de los territorios para la ejecución de proyectos económicos, bajo el supuesto de promover el desarrollo social y económico. No obstante, en muchos casos, los llamados programas de "desarrollo" han llevado al empobrecimiento de un medio ambiente $y$ al desplazamiento de las comunidades afectadas.

La Comisión Interamericana de Derechos Humanos (CIDH \& OEA 2013) reconoce que la demanda de recursos naturales que se encuentran en los territorios con presencia de pueblos indígenas está llevando a estos pueblos a un aislamiento voluntario y dejándolos en una situación aún más vulnerable. Dentro de cualquier proceso de análisis de las actividades extractivas con dichas comunidades, es importante tener en cuenta la especial relación entre la tierra y los pueblos indígenas. El territorio que habitan, puede asumirse como sus tierras o lugares concretos, donde han vivido varias generaciones, y los recursos naturales son fundamentales para la definición de su identidad, su cultura y su forma de vida. Es así como, la reivindicación de sus derechos a la tierra, significa la reafirmación de su propia identidad, por lo tanto, es vital para la supervivencia de la comunidad(Amnistía Internacional 2014).

En el estudio de la Organización de las Naciones Unidas (a través de la CEPAL) durante el Foro Permanente para las Cuestiones Indígenas (ONU 2013), se presentaron varios hallazgos sobre las afectaciones de la minería en los pueblos indígenas de México, dichos pueblos reclaman la falta de cumplimiento de las autoridades mexicanas en el respeto y protección de sus derechos consagrados en la Constitución Política de los Estados Unidos Mexicanos y en los instrumentos jurídicos internacionales; en especial la falta de participación en procesos de consulta y la obtención de su consentimiento libre, previo al otorgamiento de concesiones y de la operación de este tipo de industrias en sus territorios. Otros incumplimientos consignados fueron: la criminalización de las protestas cuando los indígenas han reclamado sus derechos, con actos de violencia que han llegado al asesinato de sus dirigentes; la pérdida de sus recursos naturales; impactos medioambientales negativos; la afectación a la salud provocada por los procesos de extracción de estos metales, entre otros. En el informe, los pueblos indígenas niegan haber sido beneficiados por las industrias extractivas.

Por otra parte, México cuenta con un marco normativo para regular la actividad minera en el país. Sin embargo, se considera que esta normativa no es indulgente con las comunidades indígenas, ni con el medio ambiente; es así como la Ley de Minería de 1992 (última reforma publicada del 2006) en el Artículo 6 decreta que la exploración, explotación y beneficio de los minerales o sustancias a que se refiere esta Ley son de utilidad pública, serán preferentes sobre cualquier otro uso o aprovechamiento del terreno, con sujeción a las condiciones que establece la misma, y únicamente por ley de carácter federal podrán establecerse contribuciones que graven estas actividades. Lo anterior quiere decir que la actividad minera en la normatividad mexicana, tiene prelación sobre cualquier otra actividad económica, incluyendo la agricultura, tal como se había comentado anteriormente. A pesar de que la actividad se encuentra regulada, se evidencian impactos negativos en las comunidades y en los recursos naturales.

De acuerdo a una revisión de la base de datos de la OCMAL (2016), se encontraron registrados 37 conflictos mineros para México, 9 de ellos están relacionados con comunidades indígenas dedicadas principalmente a la agricultura, es decir, el $24 \%$ de los casos, los cuales se presentan en la tabla 2. Los principales minerales que se encuentran involucrado dentro los conflictos son hierro, oro y plata. Por otro lado, los conflictos se reducen a afectaciones o posibles afectaciones al agua y al medio ambiente en general; los conflictos sociales están asociados con despojo, amenazas o denuncias de muertes y presión a la comunidad que está en contra de la minería.

A continuación, se presentan algunos casos puntuales, que también se encuentran registrados en la OCMAL, donde se pone de manifiesto la relación entre minería y comunidades indígenas. 
Tabla 2. Conflictos socioambientales en comunidades indígenas en México.

\begin{tabular}{|c|c|c|c|}
\hline $\begin{array}{l}\text { Ubicación del } \\
\text { Conflicto }\end{array}$ & Proyecto & $\begin{array}{l}\text { Tipo de } \\
\text { mineral }\end{array}$ & Impacto \\
\hline Guerrero & Cocula & Oro & Afectación al agua \\
\hline $\begin{array}{l}\text { San Antonio } \\
\text { de la Cal, } \\
\text { Tolimán }\end{array}$ & $\begin{array}{l}\text { Planta de } \\
\text { flotación } \\
\text { US } \\
\text { Antimony }\end{array}$ & Antimonio & Conflicto social \\
\hline $\begin{array}{l}\text { Real de } \\
\text { Catorce, San } \\
\text { Luis Potosí } \\
\text { Municipio }\end{array}$ & La luz & Plata & $\begin{array}{l}\text { Conservación del } \\
\text { grupo étnico }\end{array}$ \\
\hline $\begin{array}{l}\text { Santa María } \\
\text { de Zaniza, } \\
\text { Oaxaca }\end{array}$ & Zaniza & Hierro & $\begin{array}{l}\text { Afectaciones al } \\
\text { medio ambiente }\end{array}$ \\
\hline $\begin{array}{l}\text { San Antonio, } \\
\text { Estado de } \\
\text { Baja } \\
\text { California } \\
\text { Sur }\end{array}$ & $\begin{array}{c}\text { Mina San } \\
\text { Antonio }\end{array}$ & Oro & $\begin{array}{l}\text { Posibles } \\
\text { afectaciones al agua } \\
\text { y a la salud, } \\
\text { conflicto social }\end{array}$ \\
\hline $\begin{array}{l}\text { Municipalida } \\
\text { d de Aquila, } \\
\text { Michoacán }\end{array}$ & $\begin{array}{c}\text { Expansión } \\
\text { de la mina } \\
\text { Aquila }\end{array}$ & Hierro & Conflicto social \\
\hline $\begin{array}{l}\text { Estados de } \\
\text { Colima y } \\
\text { Jalisco }\end{array}$ & $\begin{array}{l}\text { Peña } \\
\text { Colorada }\end{array}$ & Hierro & $\begin{array}{l}\text { Afectación al medio } \\
\text { ambiente, agua, } \\
\text { vivienda, y despojo } \\
\text { de tierras }\end{array}$ \\
\hline $\begin{array}{l}\text { Zacualpán, } \\
\text { Colima }\end{array}$ & $\begin{array}{c}\text { Concesión } \\
\text { Minera } \\
201872\end{array}$ & $\begin{array}{l}\text { Cobre, } \\
\text { manganeso, } \\
\text { oro y plata }\end{array}$ & $\begin{array}{l}\text { Posibles } \\
\text { afectaciones al agua }\end{array}$ \\
\hline $\begin{array}{l}\text { Santiago de } \\
\text { Zautla, } \\
\text { Puebla }\end{array}$ & La Lupe & Molibdeno & $\begin{array}{l}\text { Posible } \\
\text { contaminación al } \\
\text { medio ambiente }\end{array}$ \\
\hline
\end{tabular}

Fuente: Información tomada de la OCMAL, 2016.

Casos de conflicto entre la industria minera y las comunidades indígenas en México

La relación entre minería y las comunidades indígenas en México se ha caracterizado desde la colonia por estar basadas en la desigualdad, la explotación y la discriminación por parte de la industria extractiva.

En la época colonial la minería tuvo un auge marcado por una tendencia creciente. Con el apoyo de la Corona Española llevó a cabo una expansión en diferentes lugares del nuevo mundo. Los indígenas fueron obligados desde muy temprano a trabajar en las minas de los españoles. Con la creación de los repartimientos, poblaciones indígenas de Michoacán y Taxco (Guerrero) fueron obligadas a trabajar en las minas. Taxco fue una de las regiones donde floreció la minería, basada en la extracción de plata. La minería requería ser abastecida, por lo tanto, motivó la diversificación de actividades y establecimiento de centros productivos en la región, este fenómeno estuvo acompañado por la existencia de conflictos por límites y linderos de las tierras (Pérez 1996). La mayoría de la mano de obra fue puesta por pobladores de las regiones cercanas a las zonas mineras, los cuales fueron despojados de sus tierras de cultivo. En las épocas de escasa mano de obra, existió otra forma de explotación adicional a los repartimientos, los indios naborios, los cuales eran trabajadores asalariados (Miranda 1992). El trabajo en las minas era muy duro, y constantemente sufrían de enfermedades como la tisis, o en el peor de los casos, los indígenas morían por accidentes dentro de las minas.

En la zona de la Sierra Madre Occidental, rica en yacimientos de oro y plata, que comprende los estados de Sonora, Sinaloa, Zacatecas, Durango, Aguascalientes, Jalisco y Nayarit, dado su difícil acceso es territorio de varios grupos indígenas (Tarahumaras, Guarojíos, Pimas, Ópatas, Tepehuanes, Huicholes, Wixarikas, etc.). Esta es una zona minera que se remonta a la colonia. Desde hace más de un siglo, las empresas mineras se han instalado para la explotación en un tiempo corto de yacimientos previamente detectados; no obstante, por la carencia de infraestructura, estas comunidades se han sumido en una condición de atraso crónico. Allí predomina el pequeño minero serrano, el cual explota los yacimientos a baja escala y con métodos antiguos, combinan la actividad minera con la siembra de maíz y fríjol. Se caracteriza por una precariedad en el trabajo y una alta inseguridad en el empleo (Sariego 1994). Si bien, no hay grandes conflictos, pero sí un nivel de pobreza marcado en estas comunidades.

En la actualidad, los conflictos continúan. Así se puede ver en el estudio realizado por Fuente y Barkin (2013), donde analizaron las relaciones entre una comunidad zapoteca y la industria minera en la Sierra Juárez de Oaxaca. Inicialmente, la industria se instala en el territorio con la promesa de promover el desarrollo; sin embargo, encontraron que las concesiones para la explotación fueron entregadas sin consentimiento de las comunidades indígenas. La expansión de esta industria extractiva impacta desde la dimensión sociocultural, especialmente en el terreno de los derechos humanos y territoriales comunitarios indígenas. A pesar de que las tierras en su gran mayoría son de propiedad comunal, el $8 \%$ del estado está concesionado y específicamente en el año 2002, le niegan la autorización a una empresa canadiense para explotar la mina Natividad (oro, plata) en la comunidad de Calpulalpan de Méndez, Oaxaca, basados en la importancia cultural y natural de su 
territorio como patrimonio de la comunidad. La comunidad en este caso, no comparte la misma visión de desarrollo basados en la extracción, la cual es impulsada por el gobierno y la industria minera. La organización social de la Sierra de Juárez no sólo ha permitido la defensa de los recursos naturales, sino también el incremento en su identidad local y regional.

Otro caso de conflicto ocasionado por la minería en la actualidad, y quizá uno de los más mencionados, es la afectación al territorio sagrado de los Wirikuta, del pueblo Wixarika, en Real del Catorce, San Luis Potosí, lugar de peregrinación estacional de los huicholes (ONU 2013). Los huicholes peregrinan cada año alrededor de 400 kilómetros para honrar a sus antepasados, hacer penitencia y recoger peyote; una peregrinación es un acto de comunión con los ancestros, los hombres huicholes hacen penitencia y ofrendas a ellos con el fin de mantener el equilibrio de la naturaleza. Según Boni et al (2015), el recorrido va desde sus comunidades hasta el lugar sagrado; es decir, los huicholes no viven en la zona minera, pero según sus tradiciones, ésta es territorio sagrado. Tanto las tradiciones ancestrales como la minería han coexistido en este lugar por más de 200 años. Esta región por su aridez había permanecido deshabitada hasta finales del siglo XVIII, cuando se descubrieron los yacimientos de plata, a hoy es una zona minera y con vocación turística (Boni et al 2015). El área ceremonial principal (Cerro Quemado), es el lugar donde finaliza la peregrinación y se hacen las ofrendas a los antepasados, se encuentra dentro del área natural protegida, sitio sagrado natural que tiene 140 mil hectáreas. Sobre este polígono se otorgaron 76 concesiones mineras a la empresa Universo de Revolution Resources Corp. y a Real Bonanza filial de First Majestic Silver Corp., por un total de 98 mil hectáreas, de las cuales están dentro de la jurisdicción de Jalisco, Durango y Nayarit. Dada la cohesión y la organización social, en el 2012 se suspende provisionalmente el proyecto minero La Luz de Real Bonanza. El conflicto tiene varios discursos, el primero es la minería sustentable y la responsabilidad social que ha venido ejerciendo la empresa minera en la zona, y el segundo es la preservación de las tradiciones y formas de vida (Boni et al 2015). No obstante, en la región la pequeña minería es de carácter individual y/o familiar, produce el $0.22 \%$ de oro y el $0.14 \%$ de plata, y no genera conflictos sociales de gran impacto (ONU 2013).

El OCMAL - Observatorio de Conflictos Mineros en América Latina (2013) registra un conflicto socioambiental en los Poblados de Puertecito de las Parotas y de los Potros, en la Sierra del Manantlán, donde habitan comunidades indígenas nahua. Allí el Consorcio italo-argentino-indio Benito Juárez Peña Colorada $S A$ de $C V$, perteneciente a la empresa Ternium-ISPAT y Mittal Steel, explota entre 250 y
300 millones de toneladas de hierro. El consorcio ha venido trabajando sin el consentimiento de la comunidad desde 1967, actualmente trabaja en el título de concesión 211011 con una vigencia hasta el año 2050, ubicado en el municipio de Cuautitlán, Jalisco. Las comunidades han denunciado violación a los derechos humanos, como accidentes provocados con el fin de desplazar a las comunidades y así apropiarse de las tierras. También afirman que la minera ha incumplido con los pagos por arrendamiento. Adicionalmente, según la OCMAL (2013), se ha denunciado en el año 2012, un desastre ambiental y social debido a la ruptura de tres cortinas de retención contenedoras de lodos y residuos tóxicos de la mina, llegando a inundar los predios y viviendas de las comunidades cercanas, y contaminando los manantiales y el río Marabasco. A esto se suma una lista de personas asesinadas, desaparecidas y amenazadas.

Los casos presentados son una muestra de la pérdida de control de las tierras que están viviendo las comunidades indígenas de México. Es cierto que la legislación en materia ambiental y de patrimonio cultural reconoce el derecho de los pueblos indígenas, pero las políticas de desarrollo económico no salvaguardan dichos derechos. Además de los casos presentados en las tablas 1 y 2, existen otras comunidades que en sus territorios se encuentran concesiones mineras.

\section{CONCLUSIONES}

La actividad minera actualmente juega un papel importante para el crecimiento económico de México, pero, dado el modelo económico que rige la industria y las políticas neoliberales ejecutadas por los gobiernos, sigue sin aportar al desarrollo de los pueblos donde aún están realizando sus actividades extractivas; no obstante, su aportación parece verse en el incremento de conflictos socioambientales con las comunidades campesinas e indígenas. Se continúa concesionando el subsuelo a empresas extranjeras con capacidad de inversión, que por lo general son de países industrializados, los cuales se quedan con la ganancia económica, dejando a los indígenas múltiples problemas sociales, de salud y ambientales, generando así un proceso de desposesión de las comunidades para la acumulación de capital en dichos países. En las regiones sólo quedan conflictos socioambientales entre la población con las empresas mineras y el gobierno.

La importancia de la tierra y el significado que ésta tiene con los pueblos indígenas, el territorio y el medio ambiente en general, ha sido el punto central de las luchas frente a la expansión de los proyectos de explotación minera. Este hecho ha permitido que los pueblos indígenas tomen una 
nueva postura frente a la organización social, de modo que les permita aprovechar los derechos que se han establecido en las normas y principios internacionales, y se genere importantes fenómenos de organización dentro de las comunidades. Sin embargo, a pesar de que la legislación mexicana reconoce a su sociedad como pluricultural, los proyectos de expansión minera ignoran los derechos de los pueblos indígenas, además de la relación ancestral y religiosa que tienen con la tierra.

Es bien sabido que los proyectos fortalecen las grandes industrias, las cuales están accediendo a concesiones para la explotación de los recursos naturales, que desde milenios han estado en posesión de los campesinos e indígenas. Es un desafío para el gobierno y para los mismos pueblos indígenas, lograr que la legislación respete el reconocimiento de la tenencia de tierras ancestrales y otros territorios, así como los recursos naturales que hay allí (suelos, agua, flora y fauna); no obstante, en la legislación actual el derecho territorial es exclusivo del Estado, que ha otorgado concesiones a largo plazo (50 años), generalmente beneficiando a empresas nacionales y transnacionales, sin una retribución adecuada a las comunidades y al mismo Estado. Estas concesiones si se revocaran en un futuro, causarían un quebranto a las finanzas públicas y generarían conflictos con las empresas mineras, además de los problemas ambientales ocasionando por las actividades extractivas.

\section{REFERENCIAS}

ACNUR - Agencia de la ONU para los Refugiados. 2008. Capítulo III: Tierras y territorios de los pueblos indígenas. Los Pueblos Indígenas de Colombia en el Umbral del Nuevo Milenio. ONU; (Fecha de acceso 15 de septiembre de 2013): 103 - $128 . \quad$ URL disponible en: www.acnur.org/biblioteca/pdf/4430.pdf?view=1

AMNISTÍA INTERNACIONAL. 2014. La larga lucha de los pueblos indígenas de américa en defensa de sus derechos. Centro de Lengua de Amnistía Internacional, Madrid. (Fecha de acceso 5 de diciembre de 2014); URL disponible en:

www.amnesty.org/en/library/asset/AMR01/002/2014/en /26a1c027-f00e-4439-a51c-

3cdae5c9ca42/amr010022014es.pdf

AZAMAR, A. \& PONCE, J. 2014. Extractivismo y desarrollo: los recursos minerales en México. Revista Problemas del Desarrollo, 179 (45): 137 - 158.

BAEZ-JORGE, F. \& GOMEZ, A. 2000. Los equilibrios del cielo y de la tierra: Cosmovisión de los nahuas de Chicontepec. Desacatos [online] (Fecha de acceso el 02 de octubre de 2015); 5: 79-94. URL disponible en: www.scielo.org. $\mathrm{mx} /$ scielo.php?script $=$ sci_arttext\&pid=S140 5-92742000000300006

BEBBINGTON, A. \& BURY, J. 2010. Minería, instituciones y sostenibilidad: desencuentros y desafíos. Revista Anthropologica. (Fecha de acceso 7 de diciembre de 2014); 28(1): 53-84. URL disponible en: http://revistas.pucp.edu.pe/index.php/anthropologica/art icle/download/1371/1324

BOEGE, E. 2013. «El despojo de los indígenas de sus territorios en el siglo xxi», La Jornada del campo, 69. (Fecha de acceso 15 de octubre de 2015); URL disponible en: www.jornada.unam.mx/2013/06/15/cam-mineria.html

BONI, A.GARIBAY, C \& MCCALL, M. K. 2015. Sustainable mining, indigenous rights and conservation: conflict and discourse in Wirikuta/Catorce, San Luis Potosi, Mexico. GeoJournal 80: 759-780.

CEPAL. 2003. Guías prácticas para situaciones específicas: manejo de riesgos y preparación para respuestas a emergencias mineras". Serie Recursos Naturales e Infraestructura. (Fecha de acceso 2 de diciembre de 2014); 57: 22 pp. URL disponible en: www.eclac.org/publicaciones/xml/0/13040/Lcl1936e.pdf

CIDH y OEA. 2013. Pueblos indígenas en aislamiento voluntario y contacto inicial en las américas: recomendaciones para el pleno respeto a sus derechos humanos. OEA/Ser.L/V/II. Doc. 47/13. (Fecha de acceso 5 de diciembre de 2014); URL disponible en: www.oas.org/es/cidh/indigenas/docs/pdf/informepueblos-indigenas-aislamiento-voluntario.pdf

COMISIÓN NACIONAL PARA EL DESARROLLO DE LOS PUEBLOS INDÍGENAS. 2014. Programa Especial de los Pueblos Indígenas 2014 - 2018. México - CDI. (Fecha de acceso 8 de mayo de 2016); 13-21 pp. URL disponible en: www.gob.mx/cms/uploads/attachment/file/32305/cdiprograma-especial-pueblos-indigenas-2014-2018.pdf

CONSTANTINO, A. 2015. ¿Quiénes son y para qué? El proceso de extranjerización de la tierra en Argentina a partir del 2002. Ambiente y Sostenibilidad 5: 43-56.

CONSTITUCION POLITICA DE LOS ESTADOS UNIDOS MEXICANOS. Vigente al 18 de julio de 2015. URL disponible en: 
Ambiente y Sostenibilidad 2016 (6): 80-96

Revista del Doctorado Interinstitucional en Ciencias Ambientales

ISSN: 2339-3122

cielo abierto y en el abasto de agua en Zacatlán, Puebla. En:

CONTRALORÍA GENERAL DE LA REPÚBLICA DE COLOMBIA. 2013. Minería en Colombia: Fundamentos para superar el modelo extractivista. Capítulos: 3 y 4. (Fecha de acceso 25 de noviembre de 2014); URL disponible en: www.escuelaing.edu.co/uploads/descargables/6412_libro_ mineria_garay_may30_2013.pdf

DELGADO-RAMOS, G. 2010. Ecología política de la minería en América Latina. Aspectos socioeconómicos, legales y ambientales de la mega minería. Centro de Investigaciones Interdisciplinarias en Ciencias y Humanidades. Ciudad de México. 520 pp.

FERRANTE, S. 2015. Economía ecológica del fracking: tensiones del autoabastecimiento energético y la reprimarización de la economía en la Argentina del siglo xxi. Ambiente y Sostenibilidad 5: 97-109.

FLORESCANO, E. 2003. Imágenes y significados del dios del maíz. En: Sin Maíz, no hay País. Conaculta. (Fecha de acceso 2 de diciembre de 2014): 35 - 55. URL disponible en: www.culturaspopulareseindigenas.gob.mx/cp/pdf/sin_ma iz_no_hay_pais.pdf

FUENTE, M. \& BARKIN, D. 2013. La minería como factor de desarrollo en la Sierra Juárez de Oaxaca: Una valoración ética. (Fecha de acceso 10 de octubre de 2015); 44(172): 123144. URL disponible en: www.scielo.org.mx/scielo.php?pid=S030170362013000100007\&script $=$ sci_arttext

GARAY, C. 2012. La nueva Geografía Minera en México. Boletín de la UNAM, Campus Morelia. No. 39: 1-3.

GAVIRIA, M. 2009. Las condiciones laborales de los trabajadores mineros en Charcas y Michoacán a fines del siglo XVIII. Reglamentos y prácticas. En: Condiciones de vida y de trabajo en la América colonial: legislación, prácticas laborales y sistemas salariales. Universidad de los Andes - Ceso. 179 - 209 pp.

GUEVARA-ROMERO, ML. TÉLLEZ-MORALES, MBR. \& FLORES-LUCERO, ML. 2015. Aprovechamiento sustentable de los recursos naturales desde la visión de las comunidades indígenas: Sierra Norte del Estado de Puebla. Revista Electrónica Nova Scientia. (Fecha de acceso 8 de octubre de 2015); 7(2): 511 - 537. URL disponible en: http://novascientia.delasalle.edu.mx/ojs/index.php/Nova /article/view/94

HERNÁNDEZ, M. MONTALVO, R. 2011. XVIII. El sueño incumplido: un estudio sobre la relación entre la minería a RAMIREZ, B. BERNAL, H. (eds). Investigación Interdisciplinaria para el Desarrollo Rural Tlaxcala Puebla: 370-393. COLPOS-Altres Costa-Amic, Puebla.

HILSON, G. \& BASU, A. 2003. Devising indicators of sustainable development for the mining and minerals industry: An analysis of critical background issues. International Journal of Sustainable Development \& World Ecology, 10(4): 319-331.

HILSON, G. 2000. Sustainable development policies in Canada's mining sector: an overview of government and industry efforts. Environmental Science \& Policy, 3: 201-211.

HILSON, G. 2002. An overview of land use conflicts in mining communities. Land Use Policy, 19: 65-73.

INEGI. 2014. Sistema de Cuentas Nacionales: Producto interno bruto. Estructura porcentual del producto interno bruto por sector de actividad económica. (Fecha de acceso 12 de octubre de 2015); URL disponible en: www.inegi.org. $\mathrm{mx} /$ sistemas/bie/cuadrosestadisticos/Gene raCuadro.aspx?s $=\mathrm{est} \& \mathrm{nc}=785 \& \mathrm{c}=24482$

INTERNATIONAL ORGANIZING COMMITTEE FOR THE WORLD MINING CONGRESSES. 2015. World Mining Data (Fecha de acceso 20 de abril de 2016); volumen 30. Viena. URL disponible en: www.en.bmwfw.gv.at/Energy/Documents/WMD2015.pdf

MARTÍNEZ-CORIA, R \& HARO-ENCINAS, J. 2015. Derechos territoriales y pueblos indígenas en México: una lucha por la soberanía y la nación. Revista Pueblos y Fronteras (Fecha de acceso 13 de mayo de 2016); 10(19): 228256. URL disponible en: www.pueblosyfronteras.unam.mx/v10n19/pdf/articulo09. pdf

MIRANDA, E. 1992. La minería en Taxco durante la Colonia. En: Revista de Estudios Históricos Tzintzun. (Fecha de acceso 12 de octubre de 2015); 15: 46-58. URL disponible en:

http://tzintzun.iih.umich.mx/num_anteriores/pdfs/tzn15 /mineria_taxco_colonia.pdf

MORAN, R. 2010. Impactos ambientales en la minería. Algunas notas sobre su costo económico. URL disponible en:

http:/ / contaminacion.conocimientos.com.ve/2010/02/imp actos-ambientales-en-la-mineria.html

NAVARRO-TRUJILLO, M \&. PINEDA-RAMÍREZ, C. 2009. 
Luchas socioambientales en América Latina y México. Nuevas subjetividades y radicalidades en movimiento. Revista Bajo el Volcán, Benemérita Universidad Autónoma de Puebla, 8 (14): 81-104.

NEURATH, J. \& PACHECO, R. Sin Fecha. Pueblos Indígenas de México y Agua: Huicholes (Wixarika). En: Atlas de culturas del agua en América Latina y el Caribe. Unesco. (Fecha de acceso 4 de diciembre de 2014); URL disponible en: www.unesco.org.uy/ci/fileadmin/phi/aguaycultura/Mexi co/05_Huicholes.pdf

OCMAL - El Observatorio de Conflictos Mineros de América Latina. 2013. Minera Peña Colorada contamina y arrasa con territorio indígena Nahua. (Fecha de acceso 4 de diciembre de 2014); URL disponible en: http:/ / basedatos.conflictosmineros.net/ocmal_db/?page $=c$ onflicto\&id $=894$

OCMAL - El Observatorio de Conflictos Mineros de América Latina. 2016. Base de datos de conflictos mineros en México. (Fecha de acceso 10 de octubre de 2016); URL disponible en: http:/ / basedatos.conflictosmineros.net/ocmal_db/?page=li sta\&idpais $=02024200$

ONU. 2013. Estudio sobre las industrias extractivas en México y la situación de los pueblos indígenas en los territorios en que están ubicadas estas industrias. Consejo Económico y Social, Foro Permanente para las Cuestiones Indígenas, Nueva York. (Fecha de acceso 2 de diciembre de 2014); URL disponible en: www.un.org/esa/socdev/unpfii/documents/2013/E_C19_ 2013_11s.pdf

ORELLANA, M. 2009. Pueblos indígenas, minería y derecho internacional. Revista Virtual REDESMA (Fecha de acceso 1 diciembre de 2014); 3(1): 21-34. URL disponible en: www.revistasbolivianas.org.bo/scielo.php?script=sci_arttex t\&pid=S1995-10782009000100005\&lng=es\&nrm=iso

PAZ, M. 2014. Conflictos socioambientales en México: ¿Qué está en disputa? En: PAZ, M. RISDELL, N. (eds). Conflictos conflictividades y movilizaciones socioambientales en México: problemas comunes, lecturas diversas: 5-58. Universidad Autónoma de México. Ciudad de México.

PÉREZ, L. 1996. Minería y Sociedad en Taxco durante el siglo XVIII. Universidad Iberoamericana, México. 204 - 222 pp.

PEREZ-RINCON, M. 2014. Injusticias ambientales en
Colombia: estadística y análisis para 95 casos. Ambiente y Sostenibilidad 4: 65-78.

REVENUE WATCH INSTITUTE. 2011. Reporte anual. Tendencia de las industrias extractivas en América Latina 2011. (Fecha de acceso 30 de noviembre de 2014); URL disponible en: www.resourcegovernance.org/sites/default/files/Reporte \%20RWI_0.pdf

SAADEN-HAZIN, M. 2013. Desarrollo minero y conflictos socioambientales. Los casos de Colombia, México y el Perú. Serie macroeconomía del desarrollo (137). Naciones Unidas. Santiago de Chile. 57pp.

SANCHEZ, L. 2000. Capítulo 22: Impactos sobre los ecosistemas. II curso internacional de aspectos geológicos de protección ambiental. (Fecha de acceso 13 de octubre de 2015); 322 - 331 pp. URL disponible en: http://www.unesco.org.uy/geo/campinaspdf/campinaspr imeras.pdf

SARIEGO, J. 1994. Minería y territorio en México: tres modelos históricos de implantación socioespacial. En: Estudios Demográficos y Urbanos. (Fecha de acceso 12 de octubre de 2015); 9(26): 327-337. URL disponible en: http://www.jstor.org/stable/40314745

SARRASIN, B. 2006. The mining industry and the regulatory framework in Madagascar: Some developmental and environmental issues. Journal of Cleaner Production. 14: 388 $-396$.

SECRETARÍA DE ECONOMÍA \& SERVICIO GEOLÓGICO MEXICANO. 2006. Anuario estadístico de la minería mexicana 2006: 49 pp.

SECRETARÍA DE ECONOMÍA \& SERVICIO GEOLÓGICO MEXICANO. 2013. Anuario estadístico de la minería mexicana 2012, edición 2013: 6-20 pp.

SECRETARÍA DE ECONOMÍA \& SERVICIO GEOLÓGICO MEXICANO. 2014a. Anuario estadístico de la minería mexicana 2014, edición 2015: 582 pp.

SECRETARÍA DE ECONOMÍA \& SERVICIO GEOLÓGICO MEXICANO. 2014b. Panorama Minero de Puebla: 40 pp.

SECRETARÍA DE ECONOMÍA. 2005. El desarrollo sostenible en la economía mexicana. (Fecha de consulta 2 de diciembre de 2014); URL disponible en: http://www.eclac.org/drni/noticias/seminarios/5/21295/ Salvador\%20Ortiz.pdf 
Ambiente y Sostenibilidad 2016 (6): 80-96

Revista del Doctorado Interinstitucional en Ciencias Ambientales

TORIXA, L. 2012. Mineras en Puebla, entre la explotación y el ecosistema. Publicado en el Periódico Digital.mx. (Fecha de acceso el 30 de noviembre de 2014); URL disponible en: http://periodicodigital.com.mx/notas/mineras_en_puebla _entre_la_explotacion_y_el_ecosistema\#.UlyJkdJmiSp

VÉLEZ-TORRES, I \& RUÍZ-TORRES, G. 2015. Extractivismo neoliberal minero y conflictos socio-ambientales en Perú y Colombia. Ambiente y Sostenibilidad 5: 3-15.

VIQUEIRA, J. 2002. La comunidad indígena en México en los estudios antropológicos e históricos. En: Encrucijadas chiapanecas. Economía, religión e identidades. Editorial Tusquets-El Colegio de México. México. 47 - 74 pp.

WOLF, E. 1971. El campesinado y sus problemas. En: Los campesinos. Editorial Labor. Barcelona. 